
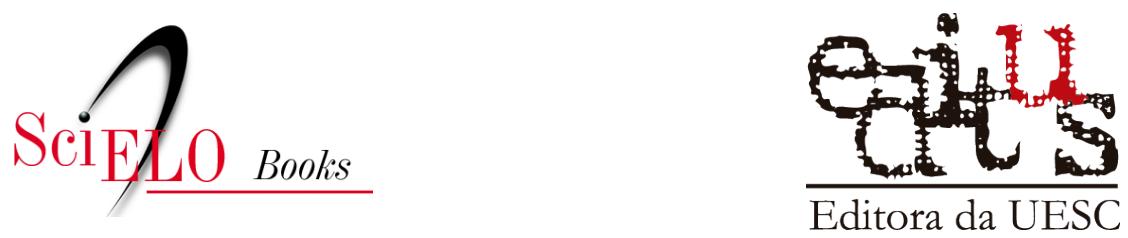

\title{
3 Movimento negro, racismo religioso e multiculturalismo
}

\author{
Ademar Cirne
}

\section{SciELO Books / SciELO Livros / SciELO Libros}

CIRNE, A. Movimento negro, racismo religioso e multiculturalismo. In: Racismo religioso em escolas da Bahia: autoafirmação e inclusão de crianças e jovens de terreiro [online]. Ilhéus, BA: Editus, 2020, pp. 49-59. Transfluência series. ISBN: 978-65-86213-16-4. https://doi.org/10.7476/9786586213294.0004.

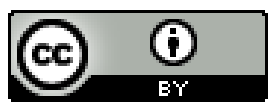

All the contents of this work, except where otherwise noted, is licensed under a Creative Commons Attribution 4.0 International license.

Todo o conteúdo deste trabalho, exceto quando houver ressalva, é publicado sob a licença Creative Commons Atribição 4.0.

Todo el contenido de esta obra, excepto donde se indique lo contrario, está bajo licencia de la licencia Creative Commons Reconocimento 4.0. 


\section{Movimento negro, racismo religioso e multiculturalismo}

Apesar do movimento negro organizado somente colocar em pauta a questão do racismo religioso a partir do século XX, e admitir esta luta como uma das suas bandeiras principais, a exemplo de ações como luta para proteção legal dos terreiros, disputa na justiça pela manutenção das cerimônias de sacralização dos animais, não se pode negar que as resistências negras, muitas vezes realizadas por iniciativas políticas dos próprios espaços sagrados de matriz africana, remontam aos séculos XVIII e XIX, na luta pessoal de lyalorixás, como foi o caso de Mãe Aninha, fundadora do llê Axé Opô Afonjá, que foi ao Rio de Janeiro reivindicar, ao presidente Getúlio Vargas, a liberação da prática do candomblé, o que resultou na alteração da lei que, até aquele presente momento, tipicava a prática das religiões de matriz africana, bem como do espiritismo e de toda e qualquer sortilégio (BRASIL, 1890).

A cidade de Salvador, local de grande concentração de casas de candomblé e de população de maioria negra, 
foi um forte exemplo da perseguição aos terreiros de Candomblé pois, muito embora Vargas tenha descriminalizado - Candomblé, a repressão injusta e arbitrária não teve fim. Para exercer o culto religioso, o terreiro necessitava de um alvará de funcionamento expedido pela Delegacia Especial de Jogos e Costumes, órgão subordinado à Secretaria Estadual de Segurança Pública. A licença policial não oferecia nenhum tipo de proteção, mesmo sendo os responsáveis obrigados a comunicarem à polícia o dia em que iriam realizar o batuque.

O exercício do culto, sem pagamento de taxas e registros na polícia, só veio acontecer em 1976 (BAHIA, 1976), quando o então governador da Bahia, Roberto Santos, assinou um Decreto Estadual, liberando os terreiros da obrigatoriedade da licença da Delegacia de Jogos e Costumes.

Para compreender melhor o movimento negro brasileiro, o autor recorreu às pesquisas do professor e pesquisador Domingues (2007), segundo o qual este movimento apresenta-se em três fases distintas, durante a república brasileira, conforme descrito a seguir.

O primeiro momento da organização do movimento negro brasileiro se estendeu de 1889 até 1937, ou seja, da proclamação da República até o início do Estado Novo. Nesse período, começam a surgir as primeiras organizações sociais em defesa da população negra. O Estado de São Paulo é pioneiro, com a fundação do clube 13 de maio dos homens pretos, em 1902, e do Centro Literário dos Homens de Cor, em 1903. Outros Estados da federação, dentre eles Rio de Janeiro, Minas Gerais, Rio Grande do Sul e Bahia, também fundaram suas organizações sociais de defesa das causas 
dos povos negros. Foi nesse momento, também, que nasceu no Brasil as primeiras organizações negras compostas somente por mulheres, entre elas a Sociedade Brinco da Princesa, no ano 1925, em São Paulo, e a Sociedade de Socorro Mútuos Princesa do Sul, em 1908, em Pelotas/RS (DOMINGUES, 2007).

Outro fato importante nesse primeiro período foi o surgimento da imprensa negra, com jornais e revistas que começaram a circular nas principais capitais do Brasil, publicando textos que tratavam das questões que afetavam a população negra.

A partir da década de 1930, com o fim da República Velha, a diminuição do poder dos coronéis e dos Estados de Minas Gerais e de São Paulo, e a organização de uma vida mais urbana com o poder cada vez mais centralizado nas mãos do Presidente Getúlio Vargas, o movimento negro percebeu a necessidade de uma organização mais sólida, para garantir e efetivar os direitos do povo negro, a partir da luta pela diminuição do racismo. Assim, em 1931, no Estado de São Paulo, foi fundada a Frente Negra Brasileira - FNB.

A segunda fase desse movimento, que se estende de 1945 a 1964, período entre a ditadura do Estado Novo e a ditadura Militar, foi marcada pela retomada das ações em favor da população negra, que tinha retrocedido quase que totalmente devido à ditadura getulista. O recomeço aconteceu com a organização da União dos Homens de Cor - UAGACÊ, fundada em 1943, em Porto Alegre e que posteriormente se expandiu por vários estados do Brasil. A sua principal finalidade era elevar o nível econômico e intelectual das pessoas de cor em todo o Brasil. 
Outra organização importante foi o Teatro Experimental do Negro - TEN, fundado em 1944, no Rio de Janeiro, por Abdias do Nascimento. Este agrupamento social rapidamente extrapolou a condição de um grupo de teatro e passou a atuar com ações mais amplas, promovendo cursos de alfabetização, de corte e costura, publicação de jornais e fundação de um Museu. A partir desse momento o movimento negro já contava com organizações em praticamente todo o país, com destaque, inclusive, para o Conselho Nacional das Mulheres Negras.

Apesar de toda essa movimentação, a primeira lei contra a discriminação racial no Brasil somente foi aprovada pelo Congresso Nacional em 1951, resultado do projeto do deputado Afonso Arinos. Nesse momento, o Brasil foi marcado pela reorganização e ascensão dos setores conservadores na política, o que culminou com o golpe civil militar de 1964 , instaurando uma ditadura que duraria por cerca de 20 anos.

Durante esse período, verificou-se um intenso retrocesso político no Brasil, com a desarticulação e desmobilização dos movimentos sociais do país, inclusive as organizações do movimento negro, que só voltaram a se reestruturar a partir do final da década de 1970, com o início do processo de abertura política e o reaparecimento das organizações sociais e do movimento negro, com destaque para o ano de 1978, quando foi fundado o Movimento Negro Unificado MNU, conceituado a seguir.

O MNU se inspirou tanto na luta a favor dos direitos civis dos negros estadunidenses, onde se projetaram lideranças como Martin Luther King, Malcom X e organizações negras marxistas, como os Panteras Negras, quanto nos 
movimentos de libertação dos países africanos, sobretudo de língua portuguesa, como Guine Bissau, Moçambique e Angola. Uma forte inspiração nacional, que converteu em escola de formação política e ideológica de várias lideranças do MNU foi uma organização marxista, de orientação trotskista, convergência socialista (DIAS, 2012).

As principais bandeiras de luta do MNU estavam ligadas à defesa da desmistificação da democracia racial brasileira e da luta para organização política das populações negras do Brasil. O movimento negro transformou-se em movimento de massa. Além do MNU, outras organizações negras reaparecem e a imprensa negra voltou a publicar jornais em todo o Brasil.

A partir desse momento, o movimento negro passou a propor intervenções na educação brasileira, construindo propostas para uma pedagogia inter-racial e multicultural, na luta pela reavaliação do papel do negro na História do Brasil, assim como uma revisão na produção dos livros didáticos que permaneciam com a visão eurocêntrica.

Com a constituição cidadã de 1988, finalmente se garantiu a liberdade de culto e a laicidade do Estado brasileiro. O movimento negro, agora, com uma nova conceituação teórica, construída a partir da década de 1970 do século XX, estabelece relações diretas com os religiosos de matriz africana, muito em função de vários coletivos negros do Brasil passarem a ter nos seus quadros muitos religiosos de matriz africana. Assim sendo o combate ao racismo religioso na sociedade e nos espaços de educação formal tem tido uma preocupação cada vez maior do movimento negro organizado. 
A partir dos anos 2000 as propostas do movimento negro organizado conseguiram atingir o Estado brasileiro, que passou a promover ações afirmativas para a população negra, estabelecendo leis como, por exemplo, a lei de cotas raciais, sancionada no mês de agosto de 2012, garantindo a reserva de $50 \%$ das matrículas por curso e turno nas 59 universidades federais e 38 institutos federais de educação, ciência e tecnologia a alunos oriundos integralmente do ensino médio público, em cursos regulares ou da educação de jovens e adultos (BRASIL, 2012).

Entre os beneficiados por este sistema estão candidatos oriundos de comunidades indígenas e quilombolas. Foram criados órgãos governamentais federais, a exemplo da Secretaria de Políticas de Promoção de Igualdade Racial - SEPPIR, das secretarias estaduais e municipais de promoção da igualdade racial que interferiram diretamente na reorganização da educação, com proposta de caráter inclusivo dos negros em todos os níveis da educação, especialmente a partir do ano de 2003, conforme já mencionado anteriormente.

Porém, apesar de tanto esforço, tanta luta e dos avanços institucionais já citados, no que se refere às políticas públicas inclusivas ainda não se alcançou uma condição satisfatória para a população negra, particularmente no que se refere a uma educação que respeite a diversidade racial, que não discrimine nem pratique o racismo religioso, especialmente com as crianças e jovens de religiões de matriz africana.

Portanto, o que se percebe é que apesar de todo esse empenho do movimento negro para garantir melhores 
condições de vida para o seu povo e de ter conseguido muitas conquistas institucionais, ainda não se superou todos os anos de escravidão e dominação, tanto no aspecto político como no cultural. Os negros ainda são parte de uma sociedade que não admite a existência do racismo, mesmo percebendo que esta prática está estruturada no país onde a maioria das pessoas cultiva o sonho da democracia racial, conceito cunhado pelo sociólogo Gilberto Freire, no século passado, que construiu o modelo de sociedade miscigenada, em que as relações eram respeitadas e entendidas por todos os grupos raciais, apesar do fato de que o desejo do "embranquecimento" da população ainda exista até hoje.

As limitações relativas à efetivação das leis que consolidam as políticas públicas para a população negra tornam-se ainda maiores quando estas se referem ao estudo dos conceitos fundamentais das religiões de matriz africana na escola. A dificuldade para se discutir conteúdos sobre religiosidade africana esbarra em um conjunto de preconceitos, diretamente relacionados com a ideia de que essas crenças trazidas da África são demonizadas e existem apenas para praticar o mal contra as pessoas, o que leva à ampliação do racismo religioso com as crianças e jovens religiosos de matriz africana, que escondem no ambiente escolar todo seu pertencimento, evitando frequentar as aulas após o período de obrigação religiosa quando precisam utilizar elementos físicos identificadores da sua prática religiosa.

Este fenômeno, que faz com que essas crianças e jovens estabeleçam o silenciamento da sua religião na escola, leva-os muitas vezes a mentirem, apresentando-se como católicos ou evangélicos para não passarem pela 
humilhação cotidiana e, até mesmo, sofrerem agressões físicas, seja dentro da escola ou no caminho que fazem da sua casa até o local de estudo. Esse racismo religioso vem se tornando uma prática que provoca a diminuição da autoestima desses estudantes e influencia na queda do seu rendimento escolar; além de, algumas vezes, provocar o abandono da escola, ampliando o índice de evasão escolar.

\begin{abstract}
A questão é de grande relevância, dado o contexto de intolerância religiosa presente nas escolas públicas, afetando o bem-estar e a aprendizagem dos estudantes. De acordo com a Pesquisa Nacional de Saúde do Escolar 2015, publicada em 2016 pelo Instituto Brasileiro de Geografia e Estatística (IBGE), 4,2\% dos estudantes de 13 a 17 anos que disseram ter sido vítimas de humilhação na escola apontaram sua religião como motivo, é a quarta principal razão de provocações feitas pelos colegas, atrás apenas da aparência do corpo, da aparência do rosto e da cor/raça, e à frente de orientação sexual e região de origem (HIROMI; GOES, 2017, p. 33).
\end{abstract}

Portanto, entendo que a superação dessa questão abordada acima perpassa o entendimento da prática do racismo religioso como sendo mais uma faceta do racismo que predomina no cotidiano dos brasileiros até os dias de hoje. Desse modo, toda perseguição, agressão, destruição de espaços religiosos, violência contra crianças e jovens de terreiro na escola são práticas de um racismo religioso, não apenas uma intolerância, pois se observa que as ações contra os religiosos de matriz africana expressam um sentimento de ódio que pode ser explicado exatamente pelo fato de serem atacados não apenas os adeptos destas religiões, mas, também, pessoas afrodescendentes, que são maioria nestes espaços. 
Racismo religioso, portanto, é o conceito que se considera mais adequado para compreender a problemática desta obra, já descrita anteriormente. Para a superação do racismo religioso, entende-se que será necessária uma transformação cultural da sociedade, o que pressupõe informação e formação a partir de conceitos introduzidos pelos movimentos multiculturalistas, contemporaneamente estudados na academia, que defendem o multiculturalismo crítico, uma das bases teórico-conceituais que esta obra adota.

Para entender a relação entre o multiculturalismo e educação será preciso compreender as concepções teóricas desse movimento, que tem origem em meados do século XIX, nos Estados Unidos, difundindo-se pelo mundo ocidental como forma de combater os conflitos surgidos devido às questões políticas, econômicas e, particularmente, ao tratamento dado a questões culturais e étnico-raciais. Portanto, considera-se que a educação multiculturalista tem papel fundamental para efetivação das políticas públicas estabelecidas pelo Estado brasileiro a partir dos anos 2000. Entretanto, sua concretização somente é possível por meio da implantação de conceitos educacionais que tenham como base a construção de uma estratégia política de reconhecimento e representação da diversidade cultural e étnico-racial, não podendo ser concebidas desassociadas do contexto de luta dos grupos culturalmente oprimidos. Para Munanga (2010, p. 42),

O multiculturalismo não poderia reduzir-se a um pluralismo sem limites; deve ser definido, pelo contrário, como a busca de uma comunicação e de uma integração parcial entre os conjuntos culturais muito tempo separados como foram os homens e as mulheres, adultos e crianças proprietários e trabalhadores 
dependentes. A vida de uma sociedade cultural organiza-se em torno de um duplo movimento de emancipação e comunicação. Sem o reconhecimento da diversidade das culturas, a ideia de recomposição do mundo arrisca cair na armadilha de um novo universalismo. Mas sem essa busca de recomposição, a diversidade cultural só pode ser a guerra de culturas.

Assim, ao aplicar os conceitos do multiculturalismo à educação nacional estaremos construindo as condições para a real efetivação das políticas públicas educacionais, por meio da construção e transformação da base curricular do ensino básico brasileiro e da realização imediata de cursos de formação continuada para professores, coordenadores e gestores, com base nos princípios da diversidade cultural e religiosa, respeito às diferenças e combate à discriminação racial e de gênero. Além disso, a transformação a partir do conceito multiculturalistapressupõe a realização de uma revisão bibliográfica nos livros didáticos a fim de desfazer a concepção eurocêntrica da história e atribuir ao negro o protagonismo histórico, apresentando para as crianças e jovens afro-brasileiros a possibilidade de conhecerem sua História, sua ancestralidade, gerando, desse modo, aumento da sua autoestima.

Mais uma vez enfatiza-se a importância de abordar o racismo religioso como eixo de destaque nesta obra, já que o assunto perpassa todos os lugares da sociedade, inclusive a escola, bem como todas as pessoas independentemente de sexo, etnia, classe social, religião e opção política. Ao relacionar intolerância religiosa ao racismo pretende-se demonstrar que a discriminação, intolerância, desrespeito sofrido pelas crianças e jovens de religião de matriz africana nas escolas são reflexos da prática racista que está presente na sociedade brasileira, um espaço onde até hoje predomina 
o conceito de raça como uma ideologia, servindo à classe dominante que, em muitos casos, abala a identidade cultural de nosso país.

Com uma elite intelectual alienada em relação aos valores culturais e com uma classe dirigente aliada ao imperialismo econômico e à sua ideologia racista, seria ingênuo acreditar- se que o atual Sistema Educacional possa vir a organizar o ensino em desacordo com as classes que dominam a sociedade e de acordo com as características multirraciais que são a base da formação da população. Ou seja, se os formuladores do ensino no Brasil ainda são, em geral, pertencentes a uma elite intelectual eurocêntrica, é lógico que o ensino está centrado nos valores culturais europeus (TRINDADE, 1994, p. 13).

Finalmente, a principal questão abordada a partir deste relato histórico do movimento negro é evidenciar que os avanços institucionais alcançados nos últimos 17 anos, relativos à redução do racismo, não foram suficientes para a construção de uma sociedade que respeite e reconheça as diferenças raciais, religiosas dentre outras, porém foram muito importantes para a afirmação dos povos e grupos sociais que compõem a sociedade, pois Ihes conferiram instrumentos para sua afirmação. Possibilitaram, também, a ampliação da informação para a sociedade em geral sobre a realidade desses grupos e raças, bem como das dificuldades que encontram para se mostrarem plenamente.

Dessa forma, passa-se ao quarto capítulo desta obra, onde está relatada a trajetória de vida deste autor. Essa trajetória foi exatamente o que substanciou esta obra, ou seja, inspirou o problema da pesquisa, mencionado e fundamentado anteriormente. 